\title{
Arsenic detection from water using a silver-modified carbon nanotubes composite electrode
}

\author{
A. Baciu, F. Manea, A. Pop \& R. Pode \\ Politehnica University of Timisoara, Romania
}

\begin{abstract}
In this study, the protocol for arsenic (III) detection from an aqueous solution using stripping voltammetry on a silver-modified synthetic zeolite-carbonnanotubes-epoxy composite electrode (CNT-AgSZ) was elaborated. Three types of electrochemical techniques were used in order to optimize the operating conditions, i.e., cyclic voltammetry, differential-pulsed voltammetry and squarewave voltammetry. Also, the mechanistic aspects related to the electrochemical behaviour of arsenic (III) on the silver-modified synthetic zeolite carbon nanotubes epoxy composite electrode were elucidated by the effect of the scan rate using cyclic voltammetry. The lowest limit of detection achieved in this study for arsenic quantification by the proposed protocol allowed the application of this scheme for practical real application for water quality assessment and monitoring.
\end{abstract}

Keywords: arsenic detection, carbon nanotube composite electrode, electrochemical techniques, water quality.

\section{Introduction}

One of the biggest concerns of several countries around the world is the contamination of water with arsenic, because such a pervasive element tends to concentrate in all aquatic matrices and especially the biota component of the ecosystem entering the trophic chain, with a great negative risk on human health. Arsenic it can be found in many forms, but in the water matrices there are two major forms: arsenite (As III), and arsenate (As V) [1, 2]. The arsenite ions are more soluble in water and approximatively 50 times more toxic than arsenate ions. Due to its toxic character, the maximum allowance concentration in water imposed by regulation is $10 \mu \mathrm{gL}^{-1}$ [3]. In this context, the necessity of 
developing the methods for the detection of arsenic in water with low detection limits and high sensitivity is imperative [4].

Accurate measurements of arsenic in water can be achieved using chemiluminescence [5], chromatography [6], and spectroscopic methods [7], yielding a good sensitivity and low limit of detection [8]. However, these methods are sophisticated and expensive requiring a certain skill for operating, which make them completely unsuitable for in-situ determination [9].

Conversely, the electrochemical methods provide a low cost, rapid and portable option for in-field determination, assuring a low limit of detection and high sensitivity. The most powerful method for arsenic detection among the electroanalytical techniques is considered to be anodic stripping voltammetry (ASV). This technique consist of two steps: one corresponds to the reduction of As (III) at the electrode surface by cathodic preconcentration of As (0) in a particular timeframe, and the second step involves the anodic stripping of As (0) deposit on the electrode surface, resulting in a faradaic response that is directly proportional to the arsenic concentration. The process corresponding to these steps can by schematically represented by:

Step 1: Deposition: $\mathrm{As}^{3+}+3 \mathrm{e}^{-} \rightarrow \mathrm{As}^{0}$;

Step 2: Anodic stripping: $\mathrm{As}^{0} \rightarrow \mathrm{As}^{3+}+3 \mathrm{e}^{-}$.

This technique can differentiate the different types of arsenic oxidation and accurately determines As (III) at low levels $[10,11]$. In order to improve the analytical performance for arsenic detection, the chemical modification of the electrode surface by using the metal nanoparticles supported or decorated the electrode surface, has attracted considerable attention [12,13]. The structure of supporting materials and the high area of these materials are very important in obtaining a high electrocatalytic effect.

The electrocatalytic effect is mainly attributed to carbon nanotubes (CNT) but the metallic catalyst present on their substrate due to its synthesis improved the electroanalytical signal [14]. The combination between CNT and metal nanoparticles is very interesting because metal reveals unique electrical, magnetic, and optical properties that can be improved by the mixing it with CNT $[15,16]$. In particular, silver-decorated carbon nanotubes-epoxy composite has been reported for ibuprofen detection [17]. Another type of chemically modified electrode is represented by the zeolite modified electrode, for which zeolite can act both as a catalyst and as support for a catalyst. Metal-doped zeolite modified electrodes have been reported to enhance the voltammetric/amperometric detection performance [18].

In this study, the protocol for arsenic (III) detection from an aqueous solution using stripping voltammetry using a silver-modified synthetic zeolite-carbonnanotubes-epoxy composite electrode was elaborated.

\section{Materials and methods}

\subsection{Materials}

The epoxy resin used in the study was Araldite ${ }^{\circledR}$ LY5052/Aradur ${ }^{\circledR} 5052$ purchased from Huntsman Advanced Materials, Switzerland. Multi-walled carbon 
nanotubes (CNT) synthesized by catalytic carbon vapor deposition were produced by Nanocyl ${ }^{\mathrm{TM}}$, Belgium.

Sodium arsenite was purchased from Merck, as analytical grade reagents and the solutions were freshly prepared with doubly distilled water.

\subsection{Preparation of a silver-modified synthetic zeolite-carbon-nanotubes-epoxy composite electrode (CNT-AgSZ)}

The dispersion of CNT in tetrahydrofuran was achieved by ultrasonication about 10 min prior to mixing with the polymer resin. After the sonication process, the solutions of CNT-THF were sonicated again with epoxy resin to obtain a more homogeneous mixture. An effective method, two roll mill (TRM), was used to prepare the electrodes in order to achieve high levels of dispersion and distribution. The ratio between the components was chosen to reach $20 \%$, wt. CNT and respective, 20\%, wt. epoxy resin. Silver-modified zeolite with a content of $0.008 \mathrm{mg} \mathrm{Ag} / \mathrm{g}$ zeolite was prepared using natural zeolite from Mirsid, Romania, with $68 \%$ wt. clinoptilolite. Synthetic zeolites were obtained from natural clinoptilolite as Si source, and sodium aluminat as Al source. Because the synthetic zeolite shows a strong alkalinity which makes it unstable in water, this was soaked in a buffer solution (sodium acetate and acetic acid). The $\mathrm{pH}$ of the mixture was kept around 5.5 for 4 hours and after solid-liquid separation, synthetic zeolite was dried at $130^{\circ} \mathrm{C}$ for 4 hours to remove the water [1]. The mixture was then poured into PVC tubes and cured in a vacuum oven at $80^{\circ} \mathrm{C}$ for $24 \mathrm{~h}$, after which it was left to cool down to room temperature, and the composite electrodes with a disc surface area of $19.63 \mathrm{~mm}^{2}$ were obtained. The electrical contact of the electrode was assured using copper wire. Figure 1 shows the schematic diagram for the CNT-AgSZ composite electrode preparation.

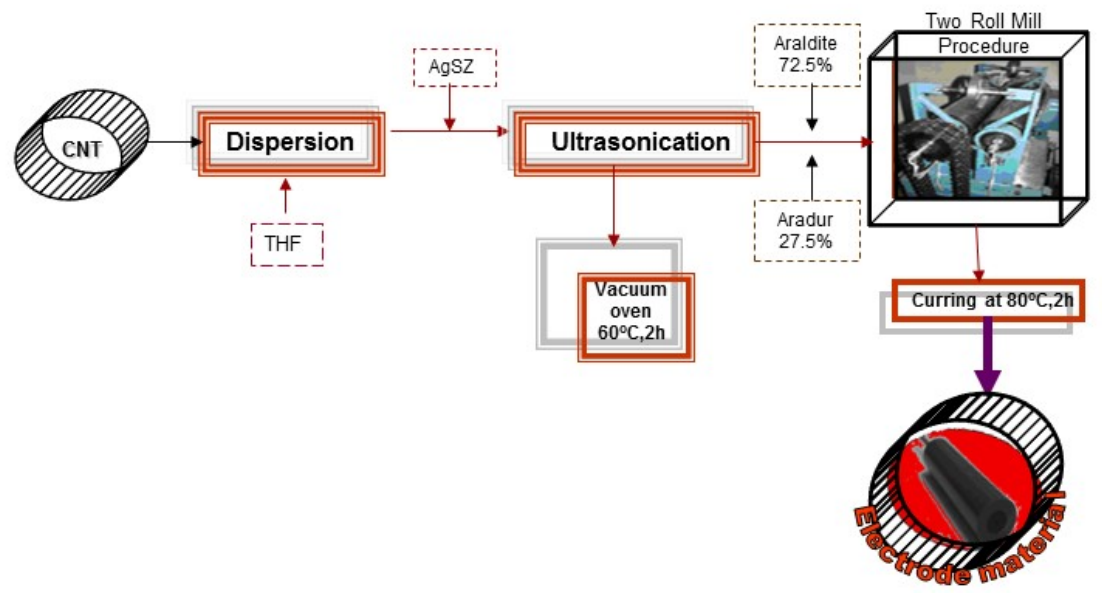

Figure 1: Schematic procedure of CNT-AgSZ composite electrode preparation. 


\subsection{Electrochemical measurements}

All electrochemical measurements were carried out using an Autolab potentiostat/galvanostat PGSTAT 302 (Eco Chemie, The Netherlands) controlled with GPES 4.9 software and a three-electrode cell, with a saturated calomel electrode (SCE) as a reference electrode, a platinum counter electrode and CNTAgSZ working electrodes.The electrochemical behaviour of the electrode envisaging arsenic detection was studied by cyclic voltammetry (CV), differential-pulsed voltammetry (DPV), and square-wave voltammetry (SWV). Before each electrochemical experiment, three repetitive cycling's between $-0.5 \mathrm{~V}$ and $+0.4 \mathrm{~V}$ vs. SCE in $0.09 \mathrm{M} \mathrm{Na}_{2} \mathrm{SO}_{4}+0.01 \mathrm{M} \mathrm{H}_{2} \mathrm{SO}_{4}$ supporting electrolyte was performed as an electrochemical pre-treatment. The detection limit was calculated as three times the standard deviation for the blank solution divided by the slope of the calibration plots.

\section{Results and discussion}

\subsection{Cyclic voltammetry measurements}

The electrochemical behavior of arsenic (III) on a silver-modified synthetic zeolite-carbon nanotubes-epoxy composite electrode (CNT-AgSZ) was studied by cyclic voltammetry (CV) taking into account the deposition step of arsenic (III) on the electrode surface by applying a preconditioning level before CV running. No response to the arsenic (III) presence was noticed on the cyclic voltammogram recorded without a preconditioning step. (The results are not shown here).

The optimum operating conditions for the deposition step prior to the all anodic stripping voltammetric experiments were formed at the deposition potential of $-0.4 \mathrm{~V} / \mathrm{SCE}$ for the deposition time of 120 seconds in relation with the best signal for arsenic (III) stripping. The deposition potential was varied between $-0.3 \mathrm{~V} / \mathrm{SCE}$ and $-0.6 \mathrm{~V} / \mathrm{SCE}$ and the time deposition ranged between 5 and 240 seconds. Figure 2 shows CVs recorded in $0.09 \mathrm{M} \mathrm{Na}_{2} \mathrm{SO}_{4}+0.01 \mathrm{M}$ $\mathrm{H}_{2} \mathrm{SO}_{4}$ supporting electrolyte at CNT-AgSZ composite electrode, after the preconditioning step, by maintaining the working electrode at the potential value of $-0.4 \mathrm{~V} / \mathrm{SCE}$ for 120 seconds.

Based on $\mathrm{CV}$ results, it can be seen that for the nanostructured carbon-based electrode containing silver supported on synthetic zeolite, a peak corresponding to arsenic stripping from the electrode surface to arsenic (III) in supporting electrolyte is evidenced. Generally, based on the literature data [19], the silver based electrodes exhibited an anodic peak corresponding to silver oxidation, to catalyze arsenic stripping. The calibration plots determined for the silver containing nanostructured based composite electrodes for As anodic stripping peak currents versus its concentration showed a good linearity with good correlation coefficients (see Figure 2(b)). 


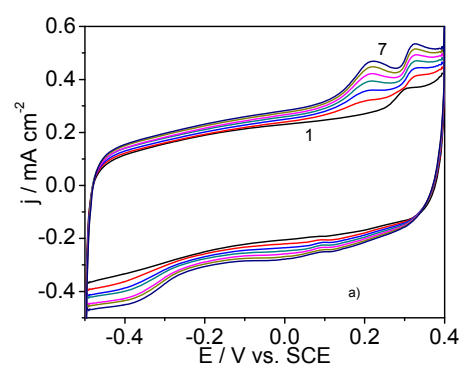

(a)

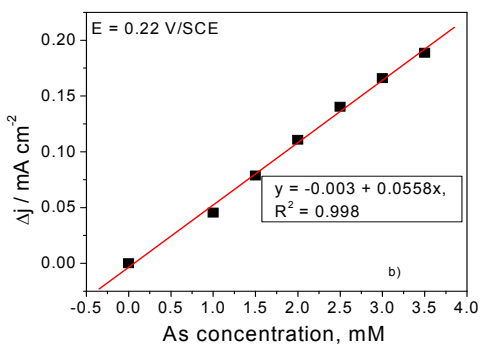

(b)

Figure 2: (a) Cyclic voltammograms recorded at CNT-AgSZ electrode in $0.09 \mathrm{M} \mathrm{Na}_{2} \mathrm{SO}_{4}+0.01 \mathrm{M} \mathrm{H}_{2} \mathrm{SO}_{4}$ supporting electrolyte (curve 1) and in the presence of $1.0,1.5,2.0,2.5,3.0,3.5 \mathrm{mM}$ As (curves 2-7) with a preconditioning of electrode at $-0.4 \mathrm{~V} / \mathrm{SCE}$ at a deposition time of $120 \mathrm{~s}$, potential scan rate: $0.05 \mathrm{Vs}^{-1}$, potential range: -0.5 to $+0.4 \mathrm{~V} / \mathrm{SCE}$. (b) The calibration plots of the current densities corresponding to the arsenic anodic stripping peaks recorded at $+0.2 \mathrm{~V} / \mathrm{SCE}$.

\subsection{Electrochemical characterization of CNT-AgSZ electrode in the presence of arsenic (III)}

Some mechanistic aspects in relation with the electrochemical behavior of arsenic (III) on CNT-AgSZ composite electrode were investigated by the effect of the scan rate on the cyclic voltammogram shapes. Figure 3 shows CVs recorded for $3 \mathrm{mM}$ As (III) in $0.09 \mathrm{Na}_{2} \mathrm{SO}_{4}+0.01 \mathrm{H}_{2} \mathrm{SO}_{4}$ supporting electrolyte at various scan rates $\left(0.01-0.2 \mathrm{Vs}^{-1}\right)$. The preconcentration step was applied before each scan rate. The linear increase of current density corresponding to stripping anodic oxidation of arsenic to arsenic (III) with the square root of the scan rate suggested a mass transfer-controlled process (Figure 3(b)). Also, the current corresponding to the silver oxidation peak increased linearly with the scan rate, which informed that this process is diffusion-controlled, as well. The peak potential shifted towards positive potential when increasing v (Figure 3(c)), but the presence of cathodic peak at $-0.4 \mathrm{~V} / \mathrm{SCE}$ corresponding to arsenic (III) reduction indicates that the electrooxidation process of arsenic is quasireversible. 


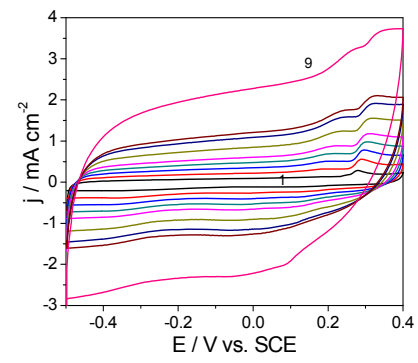

(a)

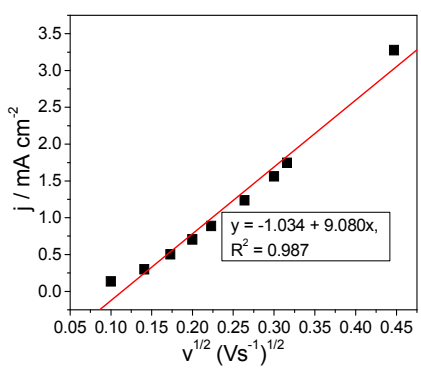

(b)

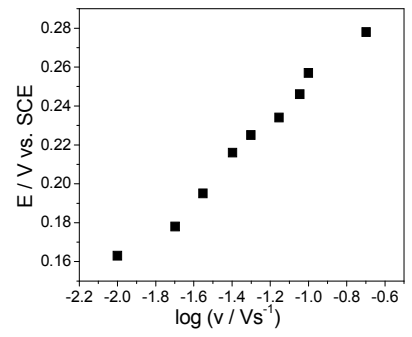

(c)

Figure 3: (a) Cyclic voltammograms of CNT-AgSZ composite electrode in $0.09 \mathrm{M} \mathrm{Na}_{2} \mathrm{SO}_{4}+0.01 \mathrm{M} \mathrm{H}_{2} \mathrm{SO}_{4}$ supporting electrolyte and in the presence of $3 \mathrm{mM} \mathrm{As}$, at a different scan rate $0.01,0.02,0.03,0.04$, $0.05,0.07,0.09,0.1,0.2 \mathrm{Vs}^{-1}$; potential range: $-0.5-+0.4 \mathrm{~V} / \mathrm{SCE}$; preconditioned at $-0.4 \mathrm{~V} / \mathrm{SCE}$ for $120 \mathrm{~s}$; (b) Plot of the current densities of the anodic peak recorded at $+0.2 \mathrm{~V} / \mathrm{SCE}$ versus the square root of the scan rate; (c) Plot of the anodic peak potential versus the logarithm of the scan rate.

\subsection{Detection measurements}

Based on the above-presented results, the detection experiments were conducted to improve the electroanalytical parameters of arsenic (III) detection by the exploitation of the operating conditions of differential-pulsed voltammetry (DPV) and square-wave voltammetry (SWV), applied subsequently to the optimum deposition step.

DPV operating parameters, the step potential and the modulation amplitude were varied. Series of DPV recorded at CNT-AgSZ composite electrode at the modulation amplitude of $0.2 \mathrm{~V}$ and various step potential values $(0.005,0.01$ and $0.02 \mathrm{~V}$ ) in the presence of various arsenic (III) concentrations are presented in Figures 4.

Also, a series of DPVs were recorded at CNT-AgSZ composite electrode under operation conditions of $0.02 \mathrm{~V}$ step potential and $0.01 \mathrm{~V}$ modulation amplitude. The sensitivity determined based on the slope of the linear calibration 
between the oxidation peak current and arsenic concentrations is much lower than those determined for the modulation amplitude of $0.2 \mathrm{~V}$ (see Table 2).

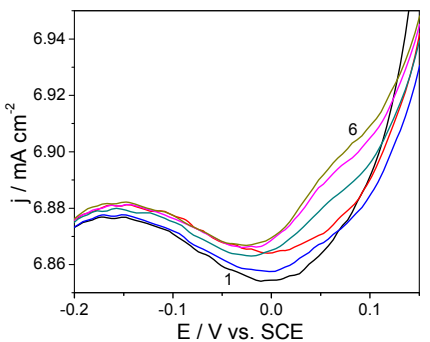

(a)

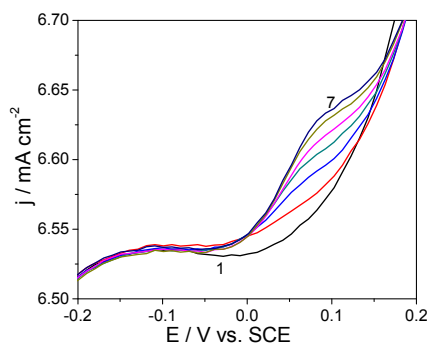

(c)

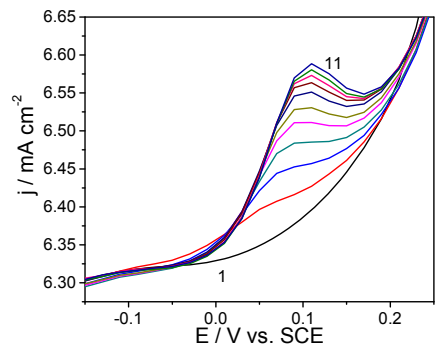

(e)

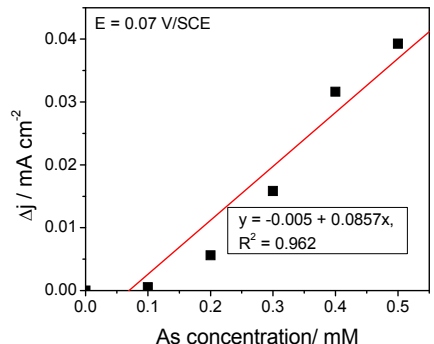

(b)

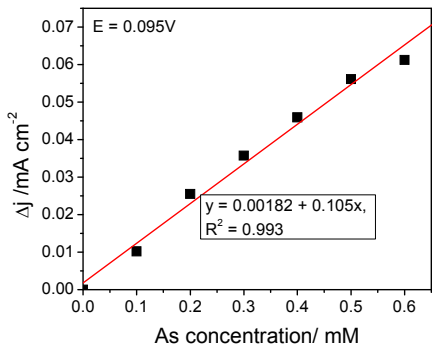

(d)

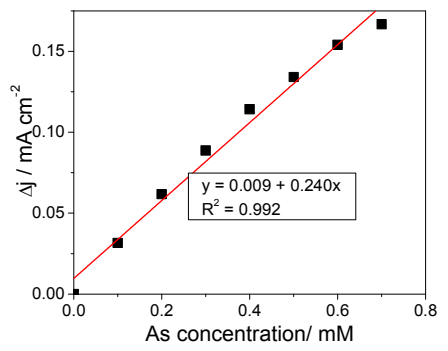

(f)

Figure 4: Differential-pulsed voltammograms recorded at CNT-AgSZ composite electrode with a $0.2 \mathrm{~V}$ modulation amplitude, between -0.25 and $+0.25 \mathrm{~V}$ vs. SCE in $0.09 \mathrm{M} \mathrm{Na}_{2} \mathrm{SO}_{4}+0.01 \mathrm{M} \mathrm{H}_{2} \mathrm{SO}_{4}$ supporting electrolyte (curve 1) and in the presence of various arsenic (III) concentrations: $0.1-1 \mathrm{mM}$ (curves 2-11) at the step potential: $0.005 \mathrm{~V}(\mathrm{a}), 0.1 \mathrm{~V}$ (c) and $0.02 \mathrm{~V}$ (e); Calibration plots of the current densities recorded at $\mathrm{E}=+0.1 \mathrm{~V} / \mathrm{SCE}$ vs. arsenic (III) concentration. 
The electroanalytical parameters for arsenic (III) detection using DPV technique at various steps potential values and modulation amplitude are presented in Tables 1 and 2.

Table 1: $\quad$ The electroanalytical parameters determined for arsenic (III) anodic stripping determination at CNT-AgSZ composite electrode using DPV technique operated at $0.2 \mathrm{~V}$ modulation amplitude.

\begin{tabular}{|c|c|c|c|c|c|}
\hline $\begin{array}{c}\text { Step } \\
\text { potential } \\
\text { value/V }\end{array}$ & $\begin{array}{c}\text { Potential } \\
\text { value } \\
\text { V/SCE }\end{array}$ & $\begin{array}{c}\text { Sensitivity } \\
\mathrm{mA} / \\
\mathrm{mMcm}^{-2}\end{array}$ & $\begin{array}{c}\text { Correlation } \\
\text { coefficient, } \mathrm{R}^{2}\end{array}$ & $\begin{array}{c}\text { Relative } \\
\text { standard } \\
\text { deviation, } \\
\mathrm{RSD} / \%\end{array}$ & $\begin{array}{c}\text { The lowest } \\
\text { limit of } \\
\text { detection, } \\
\text { LOD/mM }\end{array}$ \\
\hline 0.05 & 0.07 & 0.0857 & 0.962 & 0.125 & 0.0301 \\
\hline 0.01 & 0.095 & 0.105 & 0.993 & 0.031 & 0.04 \\
\hline 0.02 & 0.1 & 0.240 & 0.992 & 0.039 & 0.009 \\
\hline
\end{tabular}

Table 2: The electroanalytical parameters determined for arsenic (III) anodic stripping determination at CNT-AgSZ-Epoxy composite electrode using DPV technique operated at $0.02 \mathrm{~V}$ step potential.

\begin{tabular}{|c|c|c|c|c|c|}
\hline $\begin{array}{c}\text { Modulation } \\
\text { amplitude } \\
\text { value/V }\end{array}$ & $\begin{array}{c}\text { Potential } \\
\text { value } \\
\text { V/SCE }\end{array}$ & $\begin{array}{c}\text { Sensitivity } \\
\mathrm{mA} / \\
\mathrm{mMcm}^{-2}\end{array}$ & $\begin{array}{c}\text { Correlation } \\
\text { coefficient, } \\
\mathrm{R}^{2}\end{array}$ & $\begin{array}{c}\text { Relative } \\
\text { standard } \\
\text { deviation, } \\
\mathrm{RSD} / \%\end{array}$ & $\begin{array}{c}\text { The lowest } \\
\text { limit of } \\
\text { detection, } \\
\text { LOD/mM }\end{array}$ \\
\hline 0.1 & 0.17 & 0.00867 & 0.989 & 0.161 & 0.0144 \\
\hline 0.2 & 0.1 & 0.240 & 0.992 & 0.039 & 0.009 \\
\hline
\end{tabular}

The optimized operating conditions for anodic stripping voltammetry using the DPV technique are the potential step of $0.02 \mathrm{~V}$ and the modulation amplitude of $0.2 \mathrm{~V}$. Under these conditions, the SWV technique was applied at various frequency values. Only for the frequency of $10 \mathrm{~Hz}$ was the electrode response reproducible. The results of SWV under 0.02 potential step, $0.2 \mathrm{~V}$ modulation amplitude and $10 \mathrm{~Hz}$ frequency are presented in Figure 5(a). The sensitivity determined from the slope of the linear calibration (Figure 5(b)) was almost 10 times higher than the best reached by DPV.

The comparative electroanalytical parameters determined under optimized conditions using DPV and SWV are presented in Table 3.

Anodic stripping square-wave voltammetry (ASSWV) allowed us to reach the best electroanalytical parameters in relation with the sensitivity, the lowest limit of detection and quantification. Under the optimized conditions using a deposition time of 120 seconds at the potential value of $-0.4 \mathrm{~V} / \mathrm{SCE}$ and SWV (0.02 step potential, 0.2 modulation amplitude and $10 \mathrm{~Hz}$ frequency) the sensitivity of $3.119 \mathrm{~mA} / \mathrm{mMcm}^{-2}$ was determined and the lowest limit of detection of $0.005 \mathrm{mM}$ As (III). 


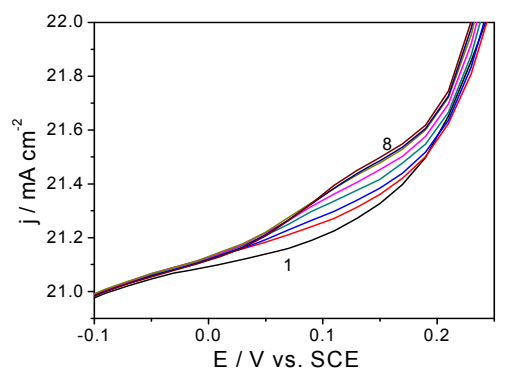

(a)

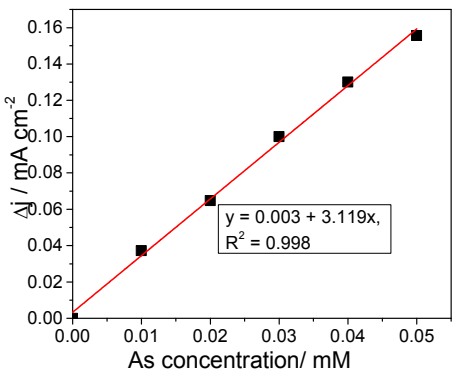

(b)

Figure 5: (a) Square-wave voltammograms recorded at CNT-AgSZ composite electrode with a $0.2 \mathrm{~V}$ modulation amplitude, $0.02 \mathrm{~V}$ step potential, $10 \mathrm{~Hz}$ frequency between -0.25 and $+0.25 \mathrm{~V}$ vs. SCE in $0.09 \mathrm{M}$ $\mathrm{Na}_{2} \mathrm{SO}_{4}+0.01 \mathrm{M} \mathrm{H}_{2} \mathrm{SO}_{4}$ supporting electrolyte (curve 1) and in the presence of different arsenic (III) concentrations: $0.01-0.07 \mathrm{mM}$ (curves 2-8); (b) Calibration plots of the current densities recorded at $\mathrm{E}=+0.14 \mathrm{~V} / \mathrm{SCE}$ vs. arsenic.

Table 3: The electroanalytical parameters determined for arsenic (III) anodic stripping determination at CNT-AgSZ composite electrode using optimized DPV and SWV techniques.

\begin{tabular}{|c|c|c|c|c|c|}
\hline Technique & $\begin{array}{c}\text { Potential } \\
\text { value } \\
\text { V/SCE }\end{array}$ & $\begin{array}{c}\text { Sensitivity } \\
\mathrm{mA} / \\
\mathrm{mMcm}\end{array}$ & $\begin{array}{c}\text { Correlation } \\
\text { coefficient, } \\
\mathrm{R}^{2}\end{array}$ & $\begin{array}{c}\text { Relative } \\
\text { standard } \\
\text { deviation, } \\
\mathrm{RSD} / \%\end{array}$ & $\begin{array}{c}\text { The lowest } \\
\text { limit of } \\
\text { detection, } \\
\mathrm{LOD} / \mathrm{mM}\end{array}$ \\
\hline DPV & 0.1 & 0.240 & 0.992 & 0.039 & 0.009 \\
\hline SWV & 0.138 & 3.119 & 0.998 & 0.179 & 0.005 \\
\hline
\end{tabular}

A recovery test was performed by analyzing three parallel tap water samples, which were spiked with $50 \mathrm{mgL}^{-1}$ arsenic (III). This test was run in $0.09 \mathrm{M}$ $\mathrm{Na}_{2} \mathrm{SO}_{4}+0.01 \mathrm{M} \mathrm{H}_{2} \mathrm{SO}_{4}$ as supporting electrolyte and a recovery of $94 \%$ with a relative standard deviation of $3.8 \%$ was found using SWV operated under optimum working conditions of $0.2 \mathrm{~V}$ modulation amplitude, $0.02 \mathrm{~V}$ step potential and $10 \mathrm{~Hz}$ frequency. Finally, the results obtained by this method were compared with those obtained by means of the standardized methods for arsenic determination [20]. Based on the result obtained, it can be concluded that the two methods lead to very close results and that the accuracy of the proposed SWV method is good. The interference effect of various anion and cation species that are common in a water matrix was investigated. These species were added at concentrations 100 times higher. No interference effect was noticed in the presence of $\mathrm{Mg}^{2+}, \mathrm{Ca}^{2+}, \mathrm{Mn}^{2+}, \mathrm{Fe}^{3+}, \mathrm{SO}_{4}{ }^{2-}, \mathrm{NO}_{3}{ }^{-}, \mathrm{CO}_{3}{ }^{2-}, \mathrm{I}^{-}, \mathrm{Cl}^{-}, \mathrm{F}^{-}$. 


\section{Conclusions}

Arsenic (III) was detected in an aqueous solution on a CNT-AgSZ composite electrode by voltammetric techniques. A certain protocol for As (III) detection was elaborated linked to the deposition and stripping steps. The deposition potential of $-0.4 \mathrm{~V} / \mathrm{SCE}$ for 120 seconds was found optimum for the deposition step. The optimum operating conditions for the stripping step consisted of a square wave voltammetry technique operated under $0.2 \mathrm{~V}$ modulation amplitude, $0.02 \mathrm{~V}$ step potential, and $10 \mathrm{~Hz}$ frequency. A good accuracy of the method was found by comparison with the standardized method for As (III) determination.

The lowest detection limit lower than $10 \mu \mathrm{gL}^{-1}$ As (III), the good accuracy and no interference of common ions from water reclaim the practical utility of this protocol in practical application of As (III) determination from water.

\section{Acknowledgements}

This work was partially supported by the strategic grant POSDRU/159/ 1.5/S/137070 (2014) of the Ministry of National Education, Romania, cofinanced by the European Social Fund - Investing in People, within the Sectoral Operational Programme Human Resources Development 2007-2013, and partially by PN-II-ID-PCE 165/2011 Grant.

\section{References}

[1] Baciu A., Pop A., Manea F., Schoonman J.,Simultaneous arsenic (III) and lead (II) detection from aqueous solution by anodic strippingsquare-wave voltammetry, Environmental Engineering and Management Journal, 13(9), pp. 2317-2323, 2014.

[2] Cinti S., Politi S., Moscone D., Palleschi G., and Arduini F., Stripping Analysis of As (III) by Means of Screen-Printed Electrodes Modified with Gold Nanoparticles and Carbon Black Nanocomposite, Electroanalysis, 26, pp. 1-9, 2014.

[3] United States Environmental Protection Agency (USEPA), Technologies and costs for removal of arsenic from drinking water. Website, Washington, D.C. http://water.epa.gov/drink/info/arsenic/upload/2005 11_10_arsenic_treatments_and_costs.pdf

[4] Toora S.K., Devi P., Bansod BK.S., Electrochemical Detection of trace amount of Arsenic (III) at Glassy Carbon Electrode modified with $\mathrm{Au} / \mathrm{Fe}_{3} \mathrm{O}_{4}$ Nanocomposites, Aquatic Procedia 4, pp. 1107-1113, 2015.

[5] Fujiwana K., Tsubota H., Kumamaru T., Ozone gas-phase chemiluminescence detection of arsenic, phosphorus, and boron in environmental waters, Analytical Sciences, 7, pp. 991-1770, 1991. 
[6] D.Q. Hung, Nekrassova O. Compton R.G., Analytical methods for inorganic arsenic in water: a review, Talanta, 64, pp. 269-277, 2004.

[7] Niedzielski P., Siepak M., Przybylek L., Siepak J., Atomic adsorption spectrometry in determination of arsenic, antimony and selenium in environmental samples, Polish Journal of Environmental Studies, 11(5), pp. 457-466, 2002.

[8] Male K.B., Hrapovic S., Santini J.M., and Luong J.H.T, Biosensor for Arsenite Using Arsenite Oxidase and Multiwalled Carbon Nanotube Modified Electrodes, Analytical Chemistry, 79(20), pp. 7831-7837, 2007.

[9] Shin S.H. and Hong H.G., Anodic Stripping Voltammetric Detection of Arsenic (III) at Platinum-Iron (III) Nanoparticle Modified Carbon Nanotube on Glassy Carbon Electrode, Bulletin of the Korean Chemical Society, 31(11), pp. 3077-3083, 2010.

[10] Cavicchioli A., La-Scalea M.A., Gitz I.G.R., Analysis and Speciation of Traces of Arsenic in Environmental, Food and Industrial samples by Voltametry: a Review, Electroanalysis,16(9), pp. 697-711, 2004.

[11] Liu Y., Huang Z., Xie Q., Sun L., Gu T., Li Z., Bu L., Yao S., Tu X., Lu $\mathrm{X}$., Luo S., Electrodeposition of electro reduced graphene oxide-Au nanoparticles composite film at glassy carbon electrode for anodic stripping voltammetric analysis of trace arsenic(III), Sensors and Actuators B, 188, pp. 894-901, 2013.

[12] Baciu A., Remes A., Ilinou E., Manea F., Picken S.J., Schoonman J., Carbon nanotubes composite for environmentally friendly sensing, Environmental Engineering Management Journal, 11, pp. 1967-1974, 2012.

[13] Dai X., Compton R.G., Gold nanoparticle modified electrodes show a reduced interference by $\mathrm{Cu}$ (II) in the detection of As (III) using anodic stripping voltammery, Electroanalysis, 17(14), pp. 1325-1330, 2005.

[14] Guo D.J., Li H.L., Highly dispersed Ag nanoparticles on functional MWNT surfaces for methanol oxidation in alkaline solution, Carbon, 43, pp. 1259-1264, 2005.

[15] Park H.S., Gong M.S., Facile preparation of nanosilver-decorated MWNTs using silver carbamate complex and their polymer composites, The Bulletin of the Korean Chemical Society, 33, pp. 483-488, 2012.

[16] Manea F., Pop A., Baciu A., Remes A., A method for fast electrochemical detection of As (III) from aqueous solutions using silver nanoparticles electrodecorated carbon nanofibers composite electrode, Registered no. OSIM:a201200555/25.07.2012, 2012.

[17] Manea F., Motoc S., Pop A., Remes A., Schoonman J., Silverfunctionalized carbon nanofibers composite electrodes for ibuprofen detection, Nanoscale Research Letters, 7, pp. 331-334, 2012.

[18] Baciu A., Remes A., Ilinou E., Manea F., Picken S.J., Schoonman J., Carbon nanotubes composite for environmentally friendly sensing, Environmental Engineering Management Journal, 11, pp. 1967-1974, 2012. 
530 Sustainable Development, Vol. 1

[19] Simm A.O., Banks C.E., Compton R.G., The electrochemical detection of arsenic (III) at a silver electrode, Electranalysis, 17(19), pp. 1727-1733, 2005.

[20] Eaton, AD., Clesceri, L.S., Rice, E.W., Greenberg, A.E., Standard Methods for the Examination of Water and Wastewater, 21st 401 ed.; American Public Health Association: 402 Washington, USA, 2005; pp. 4176. 